\title{
Effective $\mathrm{C}-\mathrm{N}-\mathrm{P}$ ratio for growth and nutrient removal efficiency of Scenedesmus obliquus in sugar mill effluent
}

\author{
V. Shashirekha ${ }^{1} \cdot$ M. Sivakumar ${ }^{2} \cdot$ S. Seshadri ${ }^{3}$ \\ ${ }^{1}$ Shri AMM Murugappa Chettiar Research Centre (MCRC), Taramani, Chennai, India \\ ${ }^{2}$ Biocon Research Limited, Electronic City, Bangalore, India \\ ${ }^{3}$ Indigenous and Frontier Technology Research (IFTR) Centre, Chennai, India
}

Received: 7 January 2016/Revised: 16 August 2016/Accepted: 19 August 2016/Published online: 7 September 2016 (C) Joint Center on Global Change and Earth System Science of the University of Maryland and Beijing Normal University and Springer-Verlag Berlin Heidelberg 2016

\begin{abstract}
Microalgae grown heterotrophically are reported to grow well and yield more biomass and metabolites when compared to photoautotrophic cultivation. In the present study, the growth of Scenedesmus obliquus in solution containing glucose, urea, and diammonium phosphate as carbon $(0.2-1.0 \%)$, nitrogen $(0.07-0.21 \%)$ and phosphorus $(0.04-0.12 \%)$ sources was evaluated. While complete utilization of carbon and nitrogen at all concentration was observed on the third day, complete phosphate uptake by the microalga was observed only at 0.04 and $0.08 \%$ concentrations. The microalga grown with $\mathrm{C}-\mathrm{N}-\mathrm{P}$ ratio of 0.2:0.14:0.08\% showed maximum biomass yield $\left(1.23 \mathrm{~g} \mathrm{~L}^{-1}\right)$ in 5 days. Furthermore, the microalga was found to adapt itself to the heterotrophic mode of growth when cultivated in the sugar mill effluent with a sugar concentration of $1.8 \mathrm{~g} \mathrm{~L}^{-1}$. Despite the complex characteristics of the substrate, $S$. obliquus exhibited maximum biomass yield of $1.28 \mathrm{~g} \mathrm{~L}^{-1}$ with 55 and $31 \%$ total protein and carbohydrate, respectively, in 12 days. Significant reduction in most of the physico-chemical parameters demonstrates the bioremediation potential of S. obliquus.
\end{abstract}

Keywords Scenedesmus obliquus · Heterotrophic growth · $\mathrm{C}-\mathrm{N}-\mathrm{P}$ ratio $\cdot$ Sugar mill effluent

Electronic supplementary material The online version of this article (doi:10.1007/s40974-016-0040-9) contains supplementary material, which is available to authorized users.

V. Shashirekha

vshashirekha@gmail.com

\section{Introduction}

Microalgae are aquatic organisms ubiquitously distributed throughout the biosphere that can grow under diverse environmental conditions. They can be grown in both open culture systems such as ponds, lakes, and canals and in highly controlled closed culture systems such as photobioreactors similar to those used in commercial fermentation processes, and certain microalgae are quite suitable for open culture conditions where the environmental conditions are very specific. In the open culture systems, though algae make use of natural sunlight for their photosynthesis, they are subject to vagaries of weather (El Bassam 1998; Amaro et al. 2011). While some microalgal species are obligate photoautotrophs, many of them are obligate heterotrophs, and a few others are mixotrophs, which drive both phototrophy and heterotrophy to use inorganic $\left(\mathrm{CO}_{2}\right)$ as well as organic carbon (Gladue and Maxey 1994; Chojnacka and Marquez-Rocha 2004; Bumbak et al. 2011). The facultative heterotrophs prefer organic carbon substrate, whenever available, over fixing $\mathrm{CO}_{2}$ (Shi et al. 2002; Kandimalla et al. 2015).

Microalgae utilize organic carbon sources, carbonates or inorganic carbon through heterotrophic mode of nutrition, which accounts for 25-50\% of their carbon (Borowitzka 1998). In general, high cell density (Vazhappilly and Chen 1998), high lipid content and lesser protein values are reported in heterotrophic growth than photosynthetic growth. Carbon assimilation in algal species such as Chlorella and Scenedesmus has been reported to get shifted from autotrophy to heterotrophy whenever the carbon source is changed from $\mathrm{CO}_{2}$ to organic carbon, or when their population gets depleted or during alternations in 
cultivation conditions (Becker 1994; Miao and Wu 2006; Nirbhay and Dolly 2011).

Though microalgae normally grow in either fresh water and/or seawater depending upon the kind of species, effluent discharges such as municipal, industrial and agricultural wastewaters also offer suitable source of nutrientrich water, making their cultivation less expensive (Becker 1994; Dalrymple et al. 2013). Nevertheless, mass cultivation of microalgae is still considered expensive than certain traditional crop production due to significant energy requirement especially at the harvesting stage (Bare et al. 1975; Wiley et al. 2009). The major nutritional requirement for microalgal growth is nitrogen, phosphorous and potassium (NPK) and certain trace elements such as magnesium and iron (Becker 1994; Mulbry et al. 2005; Dalrymple et al. 2013), and they take up these nutrients along with $\mathrm{CO}_{2}$ during photosynthesis to convert into biomass. Therefore, combinations of NPK including common agricultural fertilizers can be used to maintain stable growth rates (Weissman and Tillett 1992; Dalrymple et al. 2013). Algal cells grown under nutrient limitation conditions are reported to exhibit significant biochemical changes depending on the type and degree of nutrient limitations (Healey and Hendzel 1979; Kilham et al. 1997).

The phototrophic and heterotrophic processes in mixotrophy are reported to enhance the capability of microalgae to grow in wastewaters with increased productivity. This mode also helps to overcome problems associated with phototrophic mode of growth such as poor light penetration due to high cell densities and dark colour wastewaters (Sun et al. 2008; Wen and Chen 2003; Ip and Chen 2005; Bhatnagar et al. 2011).

The impact of commonly available sources of carbon, nitrogen and phosphorus on the growth and nutrient removal efficiency of the green microalgal isolate, Scenedesmus obliquus from the sugar mill effluent, was evaluated to understand the nutrient utilization mechanism and identify the possibilities of using sugar mill wastewater as substrate for mass cultivation of microalga.

\section{Materials and methods}

\subsection{Microalgal source}

Scenedesmus obliquus was isolated from sugar mill effluent obtained from M/s. EID Parry (I) Ltd., Nellikuppam, Cuddalore district, Tamil Nadu, India. It was periodically sub-cultured in Bold basal medium (Bold 1949) at 3000 lux (Crompton $40 \mathrm{~W}$ ) with 12/12-h light/dark cycle and at $28 \pm 2{ }^{\circ} \mathrm{C}$.

\subsection{Experimental design of nutrient optimization study}

Three sets of experiments were carried out in Erlenmeyer flasks containing varying concentrations of glucose solution $(0.1-0.5 \%)$ supplemented with different quantities of urea and diammonium phosphate $(0.01-0.03 \%)$, and the total volume was made up to $250 \mathrm{~mL}$ (Table 1). Actively growing S. obliquus culture was inoculated in all the flasks with an initial inoculum size ranging between 72 and $78 \times 10^{4}$ cells $\mathrm{mL}^{-1}$. The flasks in triplicates were maintained in an open environmental condition under diffused sunlight. During the study period, temperature, humidity and light intensity recorded daily were in the range $32-34{ }^{\circ} \mathrm{C}, 55-65 \%$ and $20-30 \mathrm{Klux}$, respectively. The culture flasks were manually swirled, periodically $5 \times$ a day to prevent settling of culture.

\subsection{Growth characterization}

The microalgal growth was evaluated by counting the cells using a haemocytometer and by biomass estimation. For the latter experiment, the culture grown in flasks was centrifuged at 10,000 rpm for $10 \mathrm{~min}$ at $4{ }^{\circ} \mathrm{C}$ and the pellet was washed twice using deionized water and then dried at $80{ }^{\circ} \mathrm{C}$ for $16 \mathrm{~h}$ in hot air oven. The dry weight (DW, $\mathrm{g} \mathrm{L}^{-1}$ ) was recorded, and the specific growth rate $\left(\mu\right.$, DW day $^{-1}$ ) was calculated using the following formula (Takagi et al. 2006):

$\mu=\frac{\ln X_{2}-\ln X_{1}}{T_{2}-T_{1}}$

Table 1 Experimental set-up with different C-N-P proportions

\begin{tabular}{ll}
\hline Experimental sets & C:N:P $(\%)$ \\
\hline Set 1 & A. $0.2: 0.07: 0.04$ \\
& B. $0.4: 0.07: 0.04$ \\
& C. $0.6: 0.07: 0.04$ \\
& D. $0.8: 0.07: 0.04$ \\
Set 2 & E. $1.0: 0.07: 0.04$ \\
& A. $0.2: 0.14: 0.08$ \\
& B. $0.4: 0.14: 0.08$ \\
& C. $0.6: 0.14: 0.08$ \\
Set 3 & D. $0.8: 0.14: 0.08$ \\
& E. $1.0: 0.14: 0.08$ \\
& A. $0.2: 0.21: 0.12$ \\
& B. $0.4: 0.21: 0.12$ \\
& C. $0.6: 0.21: 0.12$ \\
& D. $0.8: 0.21: 0.12$ \\
& E. $1.0: 0.21: 0.12$
\end{tabular}


where, $X_{1}$ and $X_{2}$ are the biomass $\left(\mathrm{g} \mathrm{L}^{-1}\right)$ measured on days $T_{1}$ and $T_{2}$, respectively.

\subsection{Nutrient uptake from glucose solution and sugar mill effluent}

The nutrient uptake efficiency of the microalga from the substrate was determined by analysing the parameters such as total sugars (Roe 1955), phosphates (Murphy and Riley 1962) and ammoniacal nitrogen (Eaton et al. 1998) on all the days of the study period, and the percentage reduction in each of the parameters was determined using the corresponding initial day value.

All the experiments were carried out in triplicates, and the values were analysed statistically using SPSS statistics package (SPSS 14). Mean values and standard deviations have been calculated. One-way ANOVA was used to determine the significant difference at $P \leq 0.05$.

A similar study was carried out using sugar mill effluent as substrate. The effluent sample obtained from M/s. EID Parry (I) Ltd. was analysed for total sugars, nitrates, phosphates, sulphates, chlorides, carbonates, calcium, magnesium, sodium, COD and BOD (Eaton et al. 1998). Other physico-chemical parameters such as $\mathrm{pH}$, total dissolved solids (TDS), dissolved oxygen (DO) were determined using the portable analyser $(\mathrm{HACH}$, Catalog NoHQ40d18). The effluent was amended with urea and diammonium phosphate, and the actively growing S. obliquus culture was inoculated with an initial inoculum of $109-110 \times 10^{4}$ cells $\mathrm{mL}^{-1}$. The microalgal growth was determined by counting the cells using haemocytometer, chlorophyll-a (Jeffrey and Humphrey 1975) and biomass estimation for a period of 2 weeks. Total protein (Bradford 1976) and total carbohydrate (Morris 1948) content of the microalgal biomass were also determined on the initial and final days. After 2 weeks, the algal culture was separated by centrifugation at $10,000 \mathrm{rpm}$ for $10 \mathrm{~min}$ at $4{ }^{\circ} \mathrm{C}$ and the supernatant was subjected to physico-chemical analyses post-algal harvest.

\section{Results and discussion}

\subsection{Carbon utilization}

The results showing complete carbon depletion in all the test samples in just $72 \mathrm{~h}$ indicate that $S$. obliquus has the ability to grow and multiply using the heterotrophic mode utilizing different dosages of carbon $(0.2-1.0 \%)$. More than $80 \%$ of carbon was found to be utilized at concentrations $0.2-0.8 \%$ in all 3 combinations of nitrogen and phosphorus amendments on the second day (Fig. 1a-c), indicating that $48 \mathrm{~h}$ is sufficient for significant carbon uptake. About $88 \%$ in the $\mathrm{C}-\mathrm{N}-\mathrm{P}$ ratio 0.2:0.21:0.12 and more than $60 \% \mathrm{C}$ utilization in ratios 0.2:0.07:0.04 and 0.2:0.14:0.08 was observed within $24 \mathrm{~h}$. In other words, carbon uptake was better and faster at low carbon $(0.2 \%)$ and high nitrogen and phosphorus concentrations than high doses of carbon $(1.0 \%)$. The data tested statistically showed marginal deviation (see supplementary data) indicating consistency in the uptake. The results further indicate that $S$. obliquus can adapt very well to varying concentrations of organic carbon substrates demonstrating its versatility to shift from phototrophic to heterotrophic growth. Some of the earlier studies have also shown the ability of Scenedesmus sp. to utilize carbon from both inorganic and organic sources. Witt and Borchardt (1960) demonstrated the adaptation of algal culture to bicarbonate as a carbon source; whenever the $\mathrm{CO}_{2}$ source was shut off, it depletes the reserve before the growth ceases at about $\mathrm{pH}$ 10. In another similar study, Abeliovich and Weisman (1978) have also reported the reduction in doubling time of the microalga cultivated in $1 \%$ glucose-supplemented substrate to $14 \mathrm{~h}$ against the normal autotrophic mode, which takes $24 \mathrm{~h}$. The growth-stimulating effect of different sugars and their varying concentrations, especially in heterotrophy, have been reported to be pronounced during light-limiting or in the dark conditions (Becker 1994). Chlorella sp. and S. quadricauda have been reported to exhibit best adaptive pattern for glucose transport system that operates by facilitated diffusion and increased glucose uptake rate in sugar refinery wastewater (Martínez et al. 1987). From the results of this study, it could be concluded that more than $92 \%$ carbon could be utilized by S. obliquus within 2 days from the substrate with $0.2-0.8 \% \mathrm{C}$ with a minimal $\mathrm{N}$ and $\mathrm{P}$ amendment.

\subsection{Nitrogen utilization}

The nitrogen utilization pattern was almost similar to that of carbon. While the nitrogen uptake within $24 \mathrm{~h}$ was relatively higher at lower concentrations of carbon, no considerable difference in the uptake pattern was observed with respect to duration and higher $\mathrm{C}-\mathrm{N}-\mathrm{P}$ ratios. Complete nitrogen utilization was recorded in all the $\mathrm{C}-\mathrm{N}-\mathrm{P}$ combinations on the third day (Fig. 2a-c) with more than $92 \%$ uptake in just $48 \mathrm{~h}$. A faster utilization of nitrogen in the form of ammonia was reported in $C$. vulgaris within $48 \mathrm{~h}$ after a 24-h lag phase (Rowley 2010). S. obliquus was reported to remove $155 \mathrm{mg}$ nitrogen from piggery wastewater diluted with synthetic media (Ji et al. 2013). The use of commercially available urea and ammonium phosphate in the present study is cheaper to nitrates of sodium or potassium or acid salts such as ammonium chloride or ammonium sulphate. A disadvantage with 
Fig. 1 Carbon utilization by $S$. obliquus in different CNP ratios a Set 1 , b Set 2 , c Set 3 (a) ๑Day 1 ๑Day 2 ๑Day 3

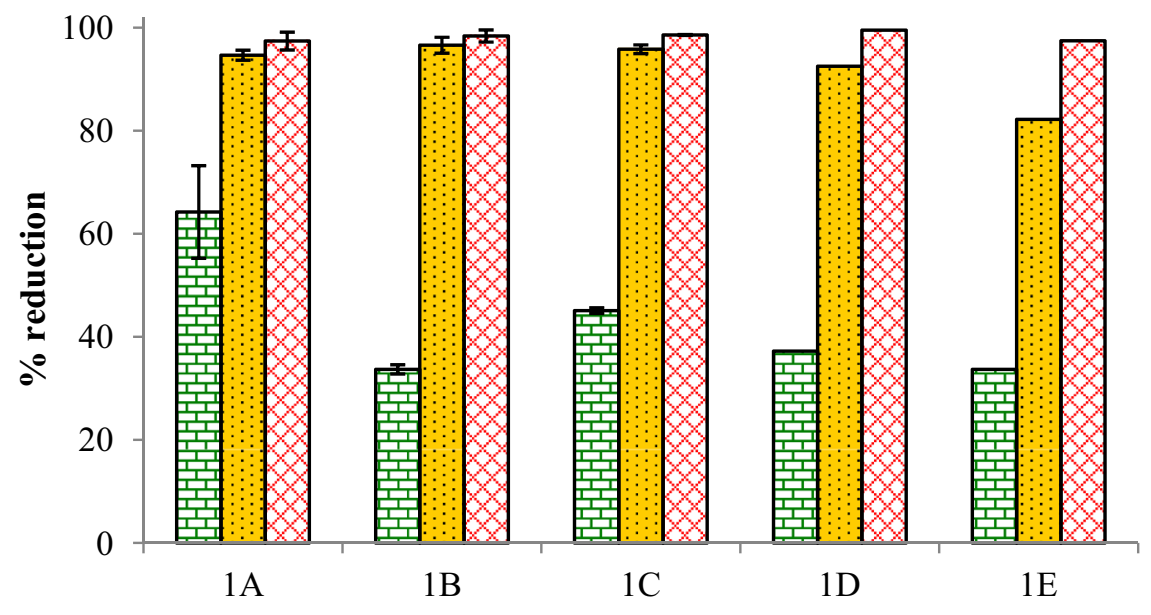

(b)

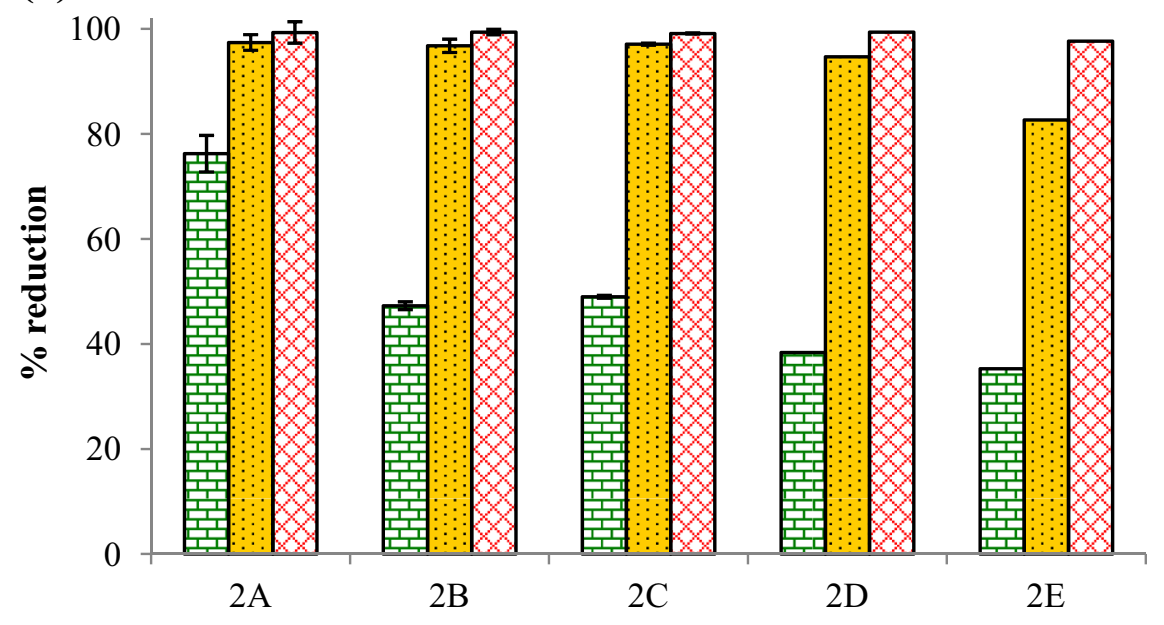

(c)

घDay 1 घDay 2 घDay 3

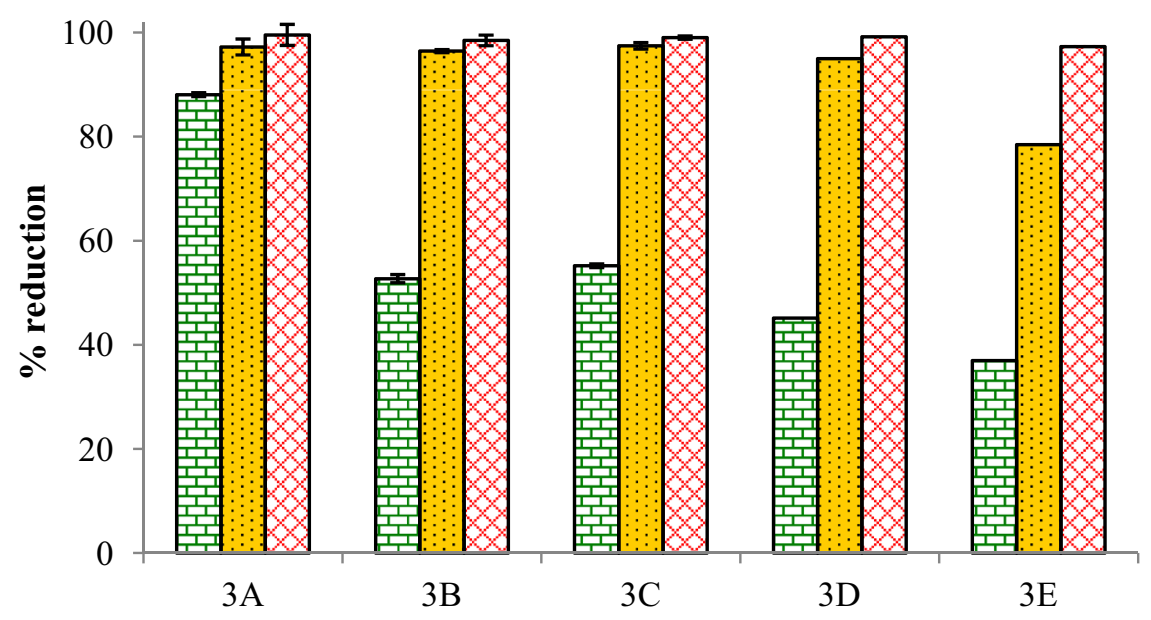

elemental nitrogen compounds or acid salts is that they require considerable metabolic energy for their assimilation and hence are not consumed by algae at the same rate as the nitrate ions (Becker 1994). Growth rate and productivity of certain microalgal species was reported to be steady and showed sharp increase in the lag phase when grown in the medium containing urea than in the sodium nitrate as nitrogen source (Makarevičienè et al. 2011). 
Fig. 2 Nitrogen utilization by S. obliquus in different CNP ratios a Set 1 , b Set 2, c Set 3

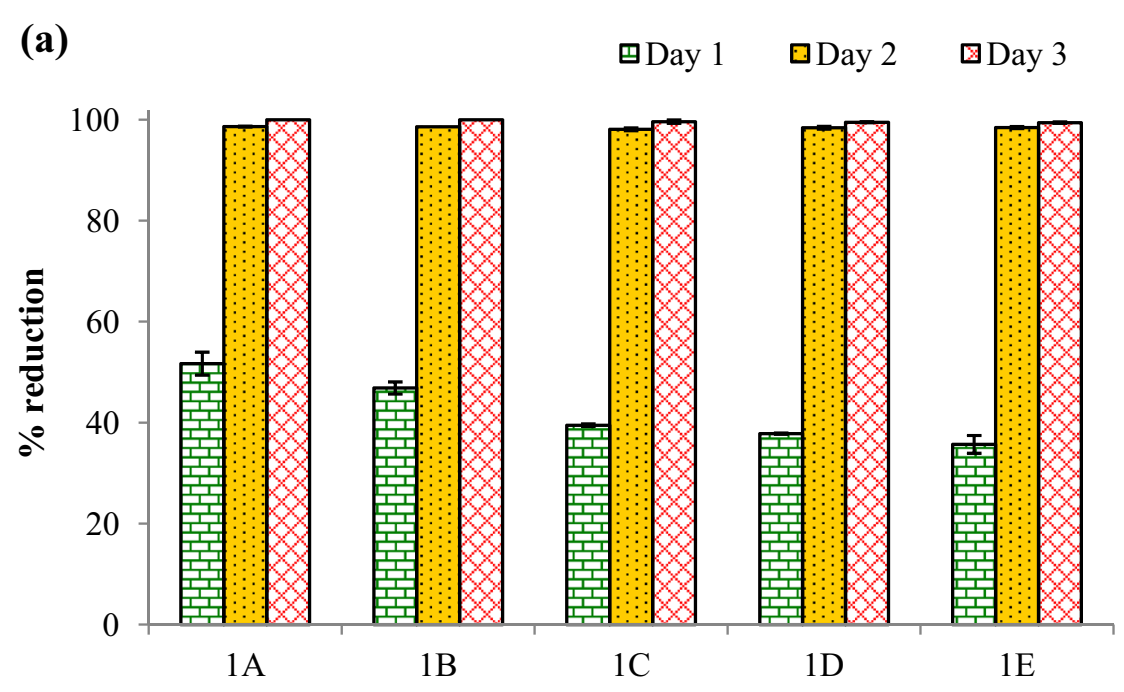

(b)
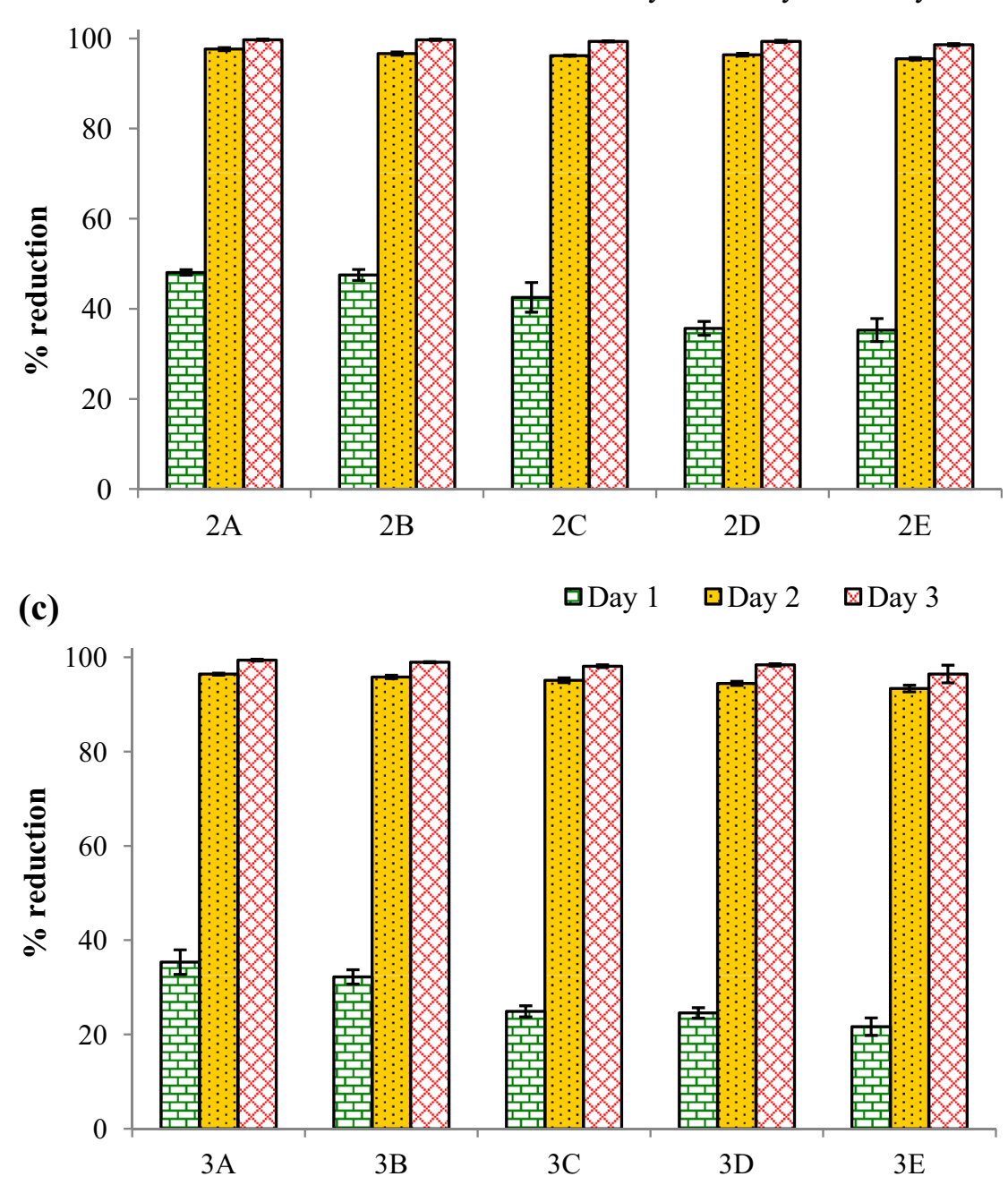


\subsection{Phosphate utilization}

Phosphate uptake pattern was quite slow when compared to carbon and nitrogen and complete utilization was achieved only at 0.04 and $0.08 \%$ concentrations with a prolonged duration varying between 3 and 5 days (Fig. $3 \mathrm{a}-\mathrm{c}$ ). However, the phosphate utilization efficiency decreased with increasing $\mathrm{C}-\mathrm{N}-\mathrm{P}$ concentrations particularly in sets $3 \mathrm{C}-$ 3E. This result corroborates well with earlier studies wherein $83 \%$ phosphate uptake by $S$. obliquus has been reported at initial concentration of $4.3 \mathrm{mg} \mathrm{L}^{-1}$ in piggery wastewater against $68 \%$ reduction in phosphate level at $9.1 \mathrm{mg} \mathrm{L}^{-1}$ ( $\mathrm{Ji}$ et al. 2013). It is, therefore, evident that lower concentrations of $\mathrm{C}-\mathrm{N}-\mathrm{P}$ are sufficient to promote algal growth. During algal metabolism, phosphates are transferred by energized transport across the plasma membrane of the algal cell through phosphorylation, involving generation of ATP from ADP, along with energy input (Becker 1994; Cai et al. 2013). Therefore, the process takes longer time than carbon and nitrogen.

Phosphates play a pivotal role in the growth and metabolism of microalgal cells. The consumption rate is reported to depend on $\mathrm{pH}$, temperature, phosphate and certain ion $\left(\mathrm{Na}^{+}, \mathrm{K}^{+}\right.$and $\left.\mathrm{Mg}^{2+}\right)$ concentrations in the surrounding environment vis-à-vis within the algal cells, which differ considerably from species to species (Rhee 1973; Brown et al. 1978; Grover 1991; Sancho et al. 1997; Cai et al. 2013). However, most freshwater microalgae are reported to tolerate low to medium phosphorus concentrations only.

\subsection{Growth and productivity}

S. obliquus grown in all $\mathrm{C}-\mathrm{N}-\mathrm{P}$ combinations exhibited a linear growth trend (Fig. $4 \mathrm{a}-\mathrm{c}$ ). While complete depletion of glucose in the media was recorded in all concentrations of carbon (0.1-0.5\%) on the third day, the cell growth was observed to continue up to 5 days. The logarithmic growth rate exhibited between days 1 and 5 in all the glucose concentrations could be attributed to the efficient transport of glucose into the cell, its effective utilization and maintenance of a perfect balance between the internal and external glucose levels.

$0.2 \%$ carbon concentration registered highest cell number viz. 357,400 and $358 \times 10^{4}$ cells in all three combinations of $\mathrm{N}$ and $\mathrm{P}$ showing best results at 0.2:0.14:0.08 \% C-N-P ratio. Beyond fifth day, the growth of microalgal cells shifted towards the stationary phase (Fig. 5a, b). The cell population results reflected the biomass productivity also yielding algal biomass of $20.5 \mathrm{~g} \mathrm{~L}^{-1}$ (wet weight) and $1.23 \mathrm{~g} \mathrm{~L}^{-1}$ (dry weight). Best yield was observed in the following order of sets $-2 A>2 B>2 C>1 A$ with a specific growth rate of 0.194 ,
$0.176,0.174$ and $0.172 \mathrm{~g}$ dry weight day $^{-1}$, respectively (Fig. 5c). However, very little variation in productivity was observed under different $\mathrm{C}-\mathrm{N}-\mathrm{P}$ proportions with the lowest and highest values registering 0.86 and $1.23 \mathrm{~g} \mathrm{~L}^{-1}$, respectively. Biomass productivity of $S$. obliquus cultivated in the cost-effective substrate in the present study was 1.36-1.42 folds higher than the values reported for $S$. dimorphus cultivated in freshwater media such as BBM, M4N, BG11, N8 and M8 (Al-Shatri et al. 2014) and S. obliquus cultivated in sophisticated closed sleeve photobioreactor (da Silva et al. 2008). Bilanovic et al. (2009) reported maximum $C$. vulgaris biomass production with lower initial $\mathrm{N}$ concentrations ranging from 285 to $427 \mathrm{mg} \mathrm{L}^{-1}$.

The reduced biomass productivity at higher $\mathrm{C}-\mathrm{N}-\mathrm{P}$ concentrations than in lower and medium ratios could be explained using the Liebig's law of minimum. The Liebig limiting nutrient is the one that declines to cellular minimum (MacIntyre and Cullen 2005). In this study, the $\mathrm{C}$ and $\mathrm{N}$ were not detectable in the growth medium beyond 3 days especially at higher concentrations (0.8-1.0 C). When nitrogen concentration is relatively low to phosphorus, the algae reduces the nitrogen allocation before the phosphorus requirement hits the minimum level. In other words, the biomass yield was nitrogen-limited; the phosphorus never was wholly utilized.

More than the nutrients present in the substrate, the metabolic mode of algae was reported to play a pivotal role in determining the biomass yield (Hsieh and Wu 2009). The mixotrophic growth of microalgae such as Chlamydomonas globosa, Chlorella minutissima and Scenedesmus bijuga was reported to result in $3-10 \times$ more biomass production than with phototrophy (Bhatnagar et al. 2011), which was apparent in this study also.

\subsection{Growth and productivity of $S$. obliquus in sugar mill effluent}

The growth pattern of $S$. obliquus in sugar effluent was quite different from the culture media containing glucose as carbon source (Fig. 6a, b). The onset of exponential phase in the glucose-containing media was immediate without a lag phase, and it lasted for a shorter duration followed by the stationary phase commencing on the fifth day itself. On the other hand, the microalga grown in sugar mill effluent showed a typical lag phase for initial 2 days followed by a steady log-phase up to 12 days attaining a maximum cell number of $\sim 445 \times 10^{4}$ cells $\mathrm{mL}^{-1}$ before reaching the stationary phase thereafter. The same trend was observed in the Chl-a content and biomass yield as well. Both these parameters witnessed a steady increase up to 12 days giving maximum yield of $1.28 \mathrm{~g}$ dry biomass and $0.0028 \mathrm{~g} \mathrm{Chl-a} \mathrm{^{-1 }}$. It was also interesting to note that 
Fig. 3 Phosphate utilization by S. obliquus in different CNP ratios a Set 1, b Set 2, c Set 3
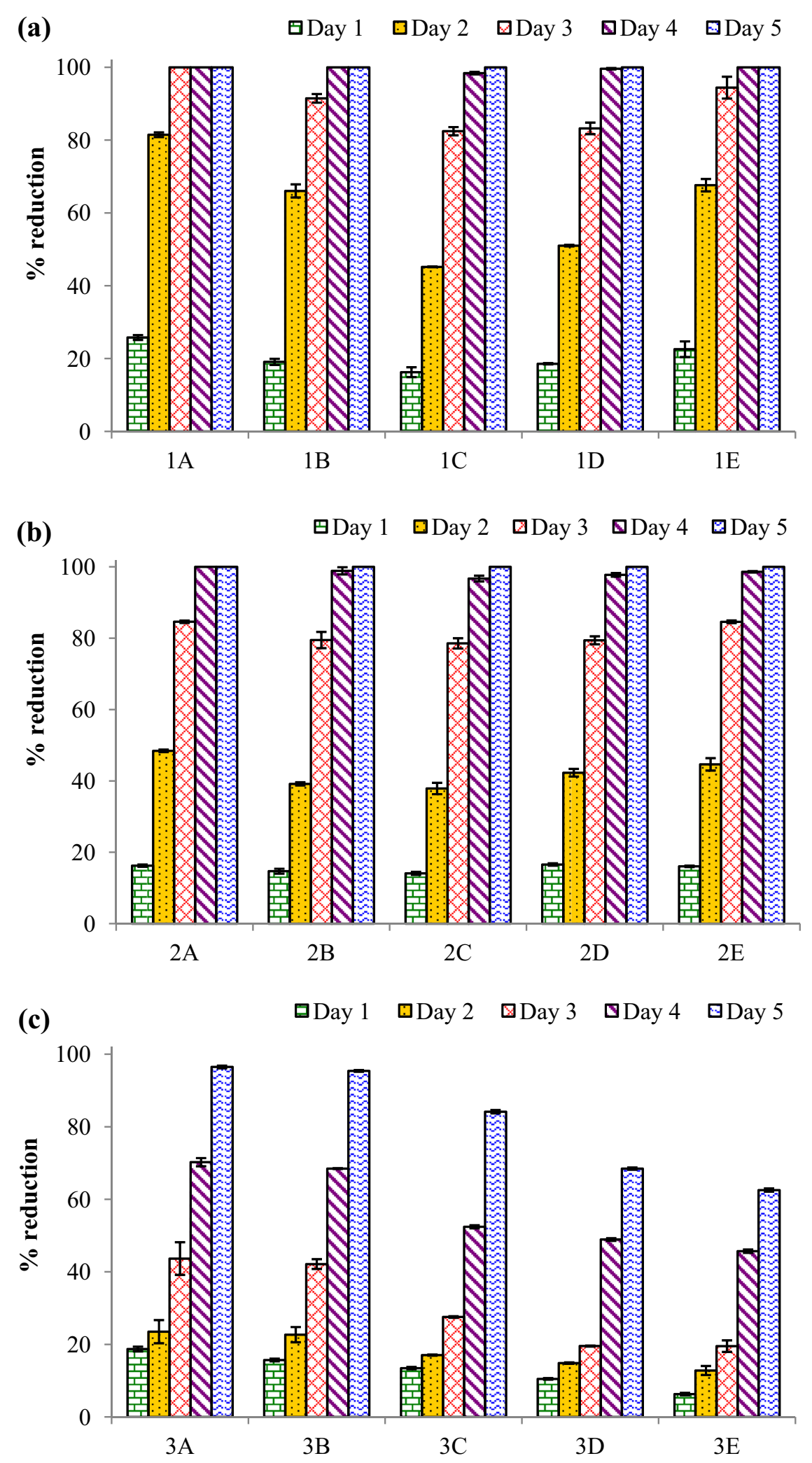

the final yield of $S$. obliquus biomass cultivated in the sugar effluent was higher than the biomass produced in the glucose solution. The prolonged exponential phase and higher biomass yield in sugar mill effluent samples could be attributed to the availability of other inorganic nutrients such as carbonates, sulphates, magnesium and sodium 
Fig. 4 Growth curve of $S$. obliquus in different CNP ratios a Set 1 , b Set 2, c Set 3
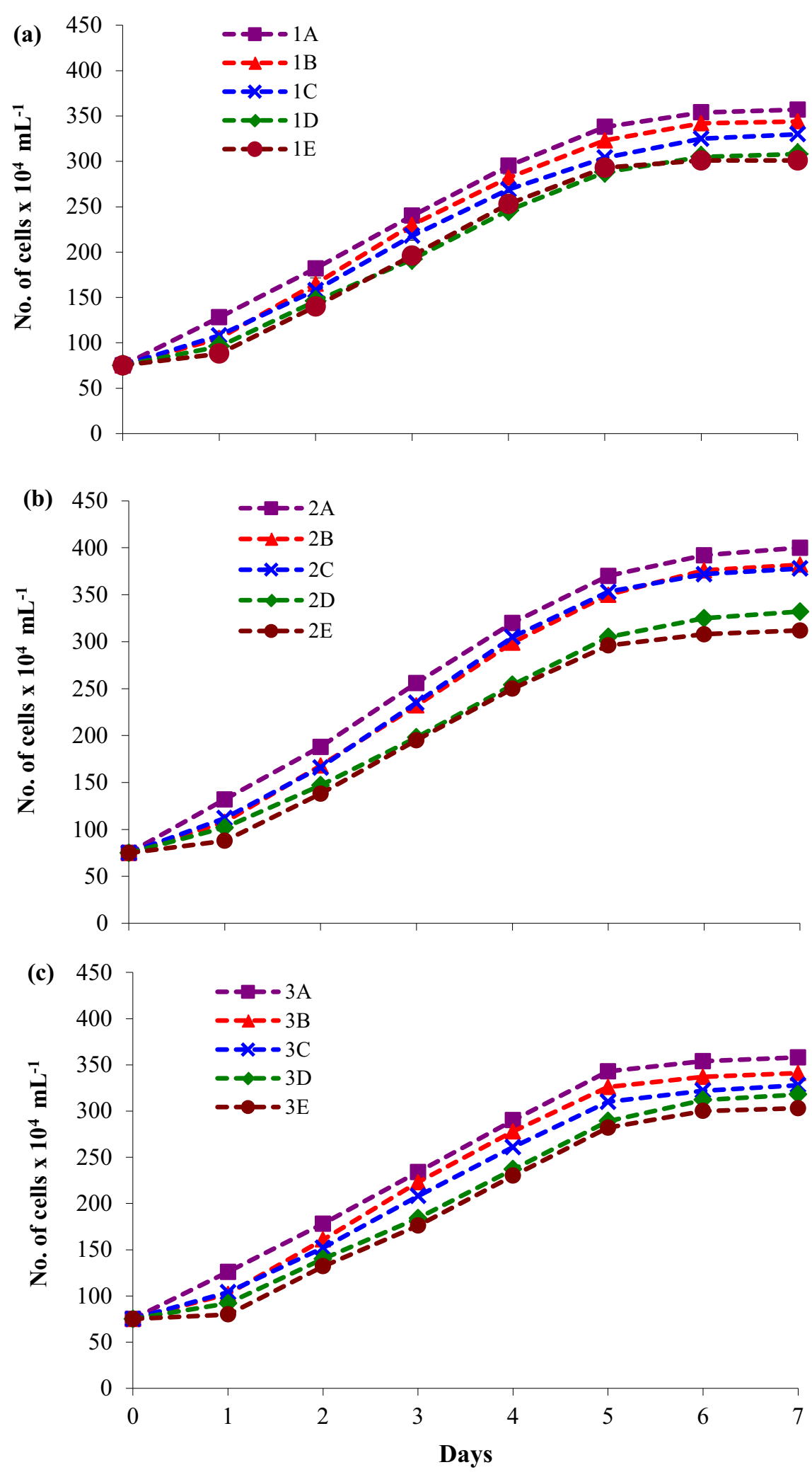

besides the presence of major nutrients viz. carbon, nitrates and phosphates. These values are higher than those reported earlier on the growth of $S$. obliquus in brewery effluent with very low nitrogen concentration, where $0.9 \mathrm{~g}$ of dry biomass per litre of culture was reported after 9 days (Mata et al. 2012). Vonshak (1986) highlighted the importance of 
Fig. 5 Biomass productivity a wet weight basis, $\mathbf{b}$ dry weight basis, $\mathbf{c}$ specific growth rate
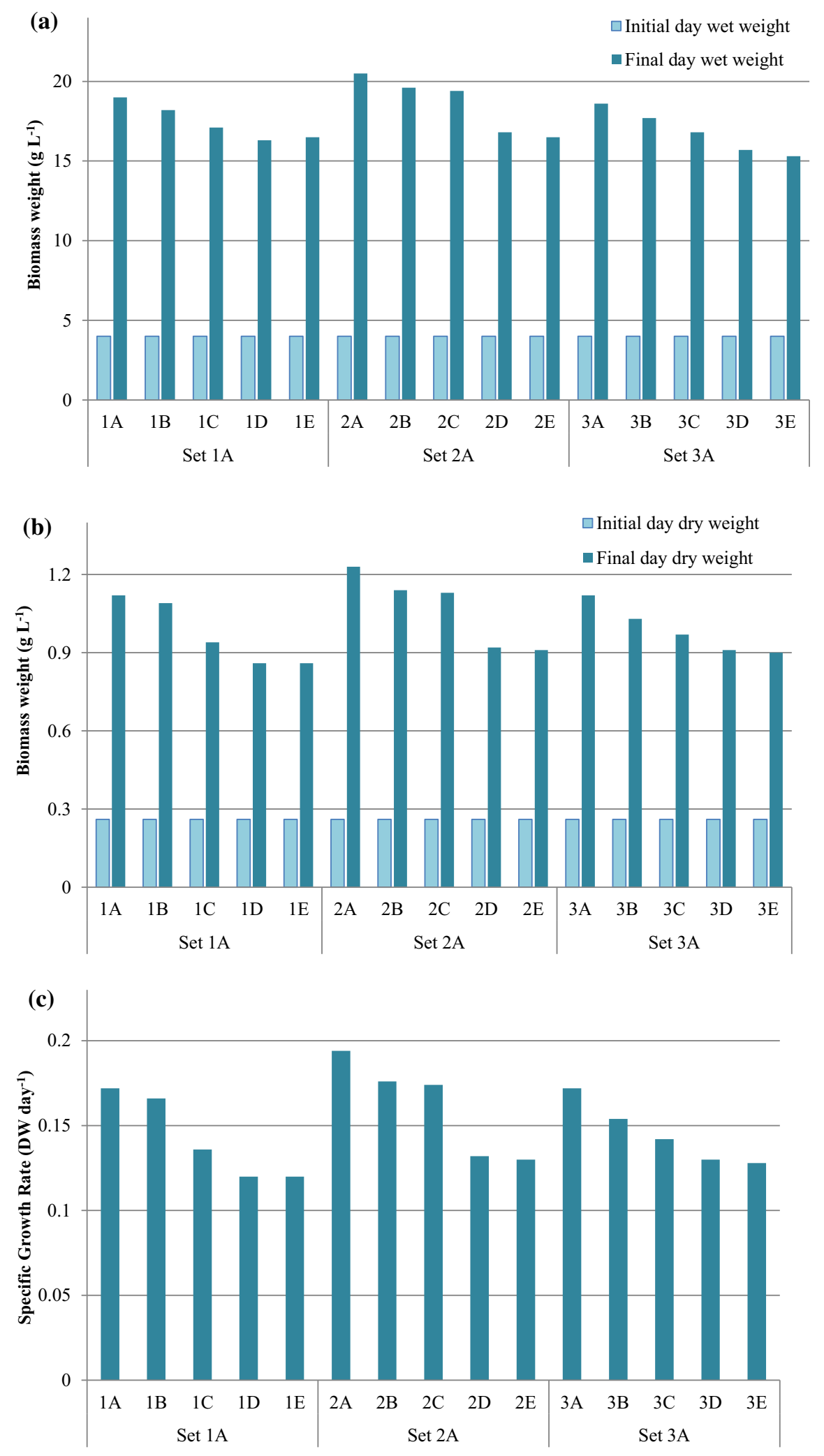

different concentrations of nutrient inputs such as potassium, magnesium, sodium, sulphates and phosphates for consideration while selecting the substrate for microalgal cultivation. Availability of these nutrients in sugar mill effluent for uptake by S. obliquus has clearly demonstrated their role in the microalgal productivity (Table 2). 

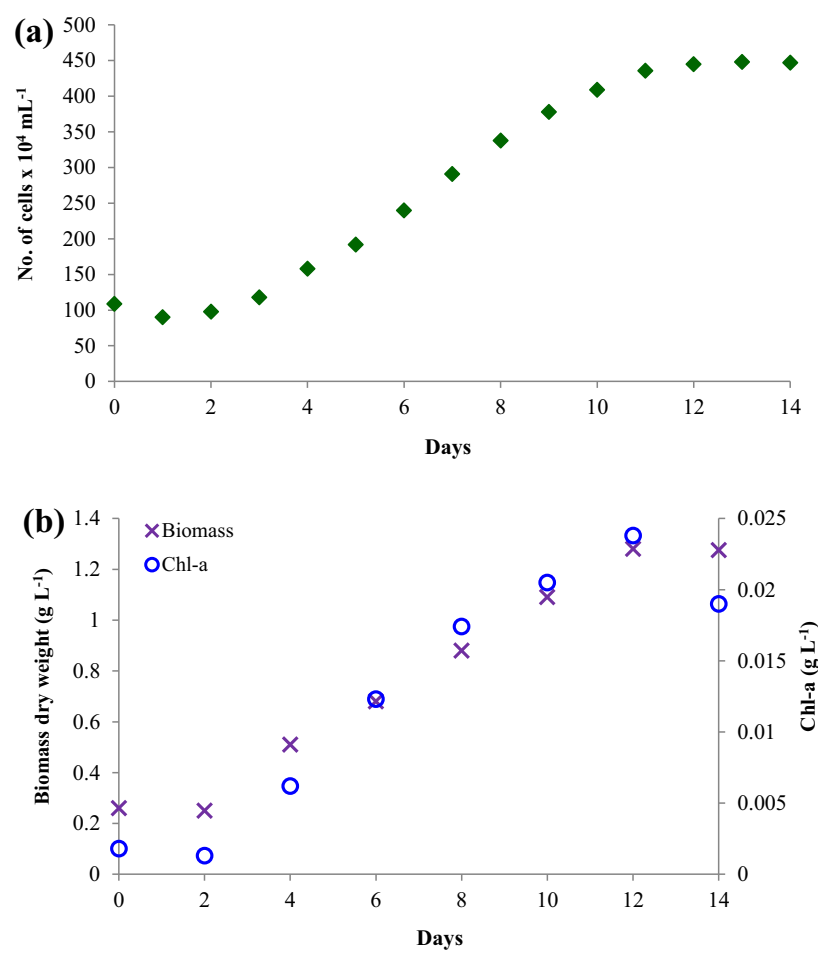

Fig. 6 Growth kinetics of $S$. obliquus in sugar mill effluent a cell population (primary axis), b biomass (primary axis) and chlorophyll-a (secondary axis)

Table 2 Physico-chemical characteristics of sugar mill effluent before and after cultivation of microalga

\begin{tabular}{llll}
\hline Sl. no. & Parameters & Before & After \\
\hline 1. & pH & 4.5 & 6.2 \\
2. & Biochemical oxygen demand & 700 & 146 \\
3. & Chemical oxygen demand & 2650 & 534 \\
4. & Dissolved oxygen & 0.2 & 5.68 \\
5. & Carbonates & 90 & BDL \\
6. & Chlorides & 60 & 32 \\
7. & Nitrates & 58 & BDL \\
8. & Phosphates & 20 & BDL \\
9. & Sulphates & 430 & 52 \\
10. & Calcium & 368 & 218 \\
11. & Magnesium & 20 & BDL \\
12. & Sodium & 32 & BDL \\
13. & Total dissolved solids & 1860 & 725 \\
14. & Total sugars & 1814 & 12 \\
\hline
\end{tabular}

All values except $\mathrm{pH}$ are expressed in $\mathrm{mg} \mathrm{L}^{-1}$

$B D L$ below detectable limit

Besides the biomass productivity, a considerable increase in the biomolecules such as proteins and carbohydrates were also observed. $308 \mathrm{mg}$ protein and $554 \mathrm{mg}$ carbohydrate were obtained per gram of dry microalgal biomass grown in sugar effluent accounting for 1.45-fold and twofold increase in protein and carbohydrate contents, respectively (Table 3). While the increase in protein levels of $S$. obliquus could be related to the bioavailable nitrogen in the sugar effluent, the increase in carbohydrate could be attributed to the adaptation of the native microalgal species to the heterotrophic mode of growth in sugar mill effluent exhibiting better assimilation and utilization of organic carbon and conversion into carbohydrates, when compared to their control counterparts used in Bold basal medium.

\subsection{Nutrient uptake by $S$. obliquus from sugar mill effluent}

The microalga was found to adapt well to the effluent quality and grow using heterotrophic mode of metabolism with excellent utilization of total sugars $(\sim 99 \%)$ from the effluent. Sugar utilization mirrored the results of cell population and biomass yield with nearly fourfold increase in their values in 2-week duration. While in glucose solutions, the microalga could utilize $0.1-0.2 \%$ sugar within 5 days, its utilization pattern in sugar effluent was quite different due to the complex nature of the latter substrate, which contains other inorganic components such as sulphates, carbonates, chlorides, nitrates, sodium, calcium, magnesium. Therefore, it is obvious that the microalga would have undergone a lag phase during which it would have acclimatized itself to the substrate. The inorganic salts present in the effluent were contributing to the dissolved solids. Since the nitrogen and phosphate levels were very low to promote microalgal growth, urea and DAP were amended to the effluent. There was a remarkable reduction in many parameters such as carbonates, nitrates, phosphates, magnesium and sodium with values recording below detectable limit indicating a complete utilization by S. obliquus. Mata et al. (2012) reported $56.9 \%$ reduction in total carbon and $20.8 \%$ reduction in nitrogen content in about 2 weeks when $S$. obliquus was grown in brewery effluent with low nitrogen content. Chlorococcum sp. RAP13 was reported to grow well in the distillery effluent under both mixotrophic and heterotrophic modes yielding more biomass and high lipid accumulation when supplemented with waste glycerol from biodiesel industry (Ummalyma and Sukumaran 2014). Besides, $88 \%$ reduction in sulphates was also observed along with reduction in TDS values. It would not be wrong to hypothesize that the presence of calcium $(60 \%)$ and chloride $(53 \%)$ could have contributed to the remaining TDS $\left(725 \mathrm{mg} \mathrm{L}^{-1}\right)$ in the alga-grown effluent.

The $\mathrm{pH}$ of the untreated sugar mill effluent was acidic due to the usage of phosphoric acid and sulphur dioxide during clarification of sugar cane juice (Manivasakam 1987). However, an increased value of 6.2 was recorded in 
Table 3 Biochemical characterization of S. obliquus

\begin{tabular}{|c|c|c|c|c|}
\hline Sl. no. & Parameters & Initial day & Final day (S. obliquus grown in sugar effluent) & Final day (S. obliquus grown in BBM) \\
\hline 1. & Protein $\left(\mathrm{mg} \mathrm{g}^{-1} \mathrm{dw}\right)$ & 382 & 554 & 418 \\
\hline 2. & Carbohydrate $\left(\mathrm{mg} \mathrm{g}^{-1} \mathrm{dw}\right)$ & 156 & 308 & 202 \\
\hline
\end{tabular}

the effluent sample after the growth of microalga. Normally, higher metabolism during active algal growth has been reported to result in the extracellular release of $\mathrm{OH}^{-}$ ions contributing to the increase in the media $\mathrm{pH}$ (Kaplan et al. 1980).

The initial COD and BOD values of the effluent were also quite far above the permissible standard values of Pollution Control Board indicating high organic load. With significant utilization of organic carbon by the microalga, nearly $80 \%$ reduction in both COD and BOD was observed. While decrease in COD could be attributed to the removal of chemical compounds by the organism, the percentage of decrease in oxygen demand was reflected in an increase in dissolved oxygen level. Elevated DO level in the effluent post-algal cultivation could be due to the photoheterotrophic metabolism of the microalga.

The presence of some fraction of organic nutrients in the industrial wastewaters is one of the major contributors for fouling, putrefaction, eutrophication, etc. Therefore, it is essential to remove them efficiently before discharging the water into external environment/water bodies. Many methodologies adopted by the industries to remove such nutrients particularly $\mathrm{N}$ and $\mathrm{P}$ from wastewaters through precipitation result in solid wastes, which limits sustainable recycling of nutrients (Duenas et al. 2003; Singh et al. 2011). Removal of many nutrients present in the sugar effluent including the $\mathrm{N}$ and $\mathrm{P}$ converted into algal biomass could be returned to the biological food chain resulting in efficient recycling of nutrients.

\section{Conclusions}

All the ratios of $\mathrm{C}-\mathrm{N}-\mathrm{P}$ used in the study supported the growth of $S$. obliquus and were utilized to not less than $60 \%$ of their initial concentration. However, the best proportion in terms of biomass yield was registered in $0.2 \% \mathrm{C}: 0.14 \% \mathrm{~N}: 0.08 \% \mathrm{P}$ demonstrating maximum biomass yield of $1.23 \mathrm{~g} \mathrm{~L}^{-1}$ on dry weight basis in 5 days. The sugar mill effluent with $1814 \mathrm{mg} \mathrm{L}^{-1}$ sugar concentration could be used as substrate for growth of $S$. obliquus. Through this study, the versatility and robustness of the native $S$. obliquus isolate was established by its ability to adapt to the heterotrophic mode of growth in the sugar mill effluent giving a maximum biomass yield of $1.28 \mathrm{~g} \mathrm{~L}^{-1}$ in 12 days. Besides sugar, reduction in other physico-chemical parameters was also recorded to a great extent depicting the bioremediation nature of the microalga. This study opens a route for the use of native $S$. obliquus isolate for nutrient removal from organic carbon-rich wastewaters like sugar mill effluents needing remediation. The wastewatergrown algal biomass could be used in various ways including poultry and/or animal feed supplement but require further in-depth studies.

Acknowledgments The authors wish to acknowledge Shri AMM Murugappa Chettiar Research Centre, Chennai for the facilities provided to undertake this work, National Programme for Carbon Sequestration (NPCS), DST, GoI, New Delhi (DST/IS-STAC/CO2SR-22/07) for providing funds and M/s. EID Parry (I) Ltd., Nellikuppam, Cuddalore Dist. for providing the effluent samples.

\section{Compliance with ethical standards}

Conflict of interest The authors declare that they have no conflict of interest.

\section{References}

Abeliovich A, Weisman D (1978) Role of heterotrophic nutrition in growth of the alga Scenedesmus obliquus in high-rate oxidation ponds. Appl Environ Microbiol 35(1):32-37

Al-Shatri AHA, Ali E, Al-Shorgani NKN, Kalil MS (2014) Growth of Scenedesmus dimorphus in different algal media and $\mathrm{pH}$ profile due to secreted metabolites. Afr J Biotechnol 13(16):1714-1720

Amaro HM, Guedes CA, Malcata FX (2011) Antimicrobial activities of microalgae: an invited review. In: Méndez-Vilas A (ed) Science against microbial pathogens: communicating current research and technological advances. FORMATEX microbiology series, Spain, pp 1272-1284

Bare WFR, Jones NB, Middlebrooks EJ (1975) Algae removal using dissolved air floatation. J Water Pollut Control Fed 47:153-169

Becker EW (1994) Microalgal biotechnology and microbiology. In: Baddiley SJ, Carey NH, Higgins IJ, Potter WG (eds) Cambridge studies in biotechnology. Cambridge University Press, New York

Bhatnagar A, Chinnasamy S, Singh M, Das KC (2011) Renewable biomass production by mixotrophic algae in the presence of various carbon sources and wastewaters. Appl Energy 88:3425-3431

Bilanovic D, Andargatchew A, Kroeger T, Shelef G (2009) Freshwater and marine microalgae sequestering of $\mathrm{CO}_{2}$ at different $\mathrm{C}$ and $\mathrm{N}$ concentrations-response surface methodology analysis. Energy Convers Manage 50(2):262-267 
Bold HC (1949) The morphology of Chlamydomonas chlamydogama sp. nov. Bull Torrey Bot Club 76:101-108

Borowitzka MA (1998) Limits to growth. In: Wong YS, Tam NFY (eds) Wastewater treatment with algae. Springer, Berlin, pp 203-226

Bradford MM (1976) A rapid and sensitive method for the quantification of microgram quantities of protein utilizing the principle of protein dye binding. Anal Biochem 72:248-254

Brown EJ, Harris RF, Koonce JF (1978) Kinetics of phosphate uptake by aquatic microorganisms: deviations from a simple MichaelisMenten equation. Limnol Oceanogr 23(1):26-34

Bumbak F, Cook S, Zachleder V, Hauser S, Kovar K (2011) Best practices in heterotrophic high-cell-density microalgal processes: achievements, potential and possible limitations. Appl Microbiol Biotechnol 91(1):31-46

Cai T, Park S, Li Y (2013) Nutrient recovery from wastewater streams by microalgae: status and prospects. Renew Sustain Energy Rev 19:360-369

Chojnacka K, Marquez-Rocha FJ (2004) Kinetic and stoichiometric relationships of the energy and carbon metabolism in the culture of microalgae. Biotechnology 3(1):21-34

da Silva TL, Reis A, Medeiros R, Oliveira AC, Gouveia L (2008) Oil production towards biofuel from autotrophic microalgae semicontinuous cultivations monitorized by flow cytometry. Appl Biochem Biotechnol 159(2):568-578

Dalrymple OK, Halfhide T, Udom I, Gilles B, Wolan J, Zhang Q, Ergas S (2013) Wastewater use in algae production for generation of renewable resources: a review and preliminary results. Aquat Biosyst 9:2

Duenas JF, Alonso JR, Rey AF, Ferrer AS (2003) Characterization of phosphorus forms in wastewater treatment plants. J Hazard Mater 97:1-3

Eaton AD, Clesceri LS, Greenberg AE, Franson MAH (1998) Standard methods for the examination of water and wastewater, 20th edn. American Public Health Association, Washington

El Bassam N (1998) Energy plant species: their use and impact on environment and development. James \& James (Science Publishers) Ltd, London

Gladue RM, Maxey JE (1994) Microalgal feeds for aquaculture. J Appl Phycol 6(2):131-141

Grover JP (1991) Non-steady state dynamics of algal population growth: experiments with two chlorophytes. J Phycol 27:70-79

Healey FP, Hendzel LL (1979) Indicators of phosphorus and nitrogen deficiency in five algae in culture. J Fish Res Board Can 36:1364-1369

Hsieh $\mathrm{CH}$, Wu WT (2009) Cultivation of microalgae for oil production with a cultivation strategy of urea limitation. Bioresour Technol 100:3921-3926

Ip PF, Chen F (2005) Production of astaxanthin by the green microalga Chlorella zofingiensis in the dark. Process Biochem 40:733-738

Jeffrey SW, Humphrey GF (1975) New spectrophotometric equations for determining chlorophyll a, b, $c_{1}$ and $c_{2}$ in higher plants, algae and natural phytoplankton. Biochem Physiol Pflanzen 167:191-194

Ji MK, Abou-Shanab RAI, Hwang JH, Timmes TC, Kim HC, Oh YK, Jeon BH (2013) Removal of nitrogen and phosphorus from piggery wastewater effluent using the green microalga Scenedesmus obliquus. J Environ Eng 139(9):1198-1205

Kandimalla P, Desi S, Vurimindi H (2015) Mixotrophic cultivation of microalgae using industrial flue gases for biodiesel production. Environ Sci Pollut Res 23(10):1-10

Kaplan A, Badger MR, Berry JA (1980) Photosynthesis and the intracellular inorganic carbon pool in the blue green alga Anabaena variabilis: response to external $\mathrm{CO}_{2}$ concentration. Planta 149(3):219-226
Kilham SS, Kreeger DA, Goulden CE, Lynn SG (1997) Effect of nutrient limitation on biochemical constituents of Ankistrodesmus falcatus. Freshw Biol 38:591-596

MacIntyre H, Cullen J (2005) Using cultures to investigate the physiological ecology of microalgae. In: Andersen RA (ed) Algal culturing techniques. Academic Press, Burlington, pp 287-326

Makarevičienė V, Andrulevičiūtė V, Skorupskaitè V, Kasperovičienè J (2011) Cultivation of microalgae Chlorella sp. and Scenedesmus sp. as a potentional biofuel feedstock. Environ Res Eng Manag 3(57):21-27

Manivasakam N (1987) Industrial effluents origin, characteristics, effects, analysis and treatment. Sakthi Publications, Kovai Pudur

Martínez F, Avendaño MC, Marco E, Orús MI (1987) Algal population and auxotrophic adaptation in a sugar refinery wastewater environment. J Gen Appl Microbiol 33:331-341

Mata TM, Melo AC, Simões M, Caetano NS (2012) Parametric study of a brewery effluent treatment by microalgae Scenedesmus obliquus. Bioresour Technol 107:151-158

Miao X, Wu Q (2006) Biodiesel production from heterotrophic microalgal oil. Bioresour Technol 97(6):841-846

Morris DL (1948) Quantitative determination of carbohydrates with Dreywood's anthrone reagent. Science 107(2775):254-255

Mulbry W, Westhead EK, Pizarro C, Sikora L (2005) Recycling of manure nutrients: use of algal biomass from dairy manure treatment as a slow release fertilizer. Bioresour Technol 96(4):451-458

Murphy J, Riley JP (1962) A modified single solution method for the determination of phosphate in natural waters. Anal Chim Acta 27:31-36

Nirbhay KS, Dolly WD (2011) Microalgae as second generation biofuel. A review. Agron Sustain Dev 31:605-629

Rhee GY (1973) A continuous culture study of phosphate uptake, growth rate and polyphosphate in Scenedesmus sp. J Phycol 9:495-506

Roe JH (1955) The determination of sugar in blood and spinal fluid with anthrone reagent. J Biol Chem 212:335-343

Rowley WM (2010) Nitrogen and phosphorus biomass-kinetic model for Chlorella vulgaris in a biofuel production scheme. Master of science thesis, Air Force Institute of Technology, Air University

Sancho MEM, Castillo JMJ, Yousfi EF (1997) Influence of phosphorus concentration on the growth kinetics and stoichiometry of the microalga Scenedesmus obliquus. Process Biochem 32(8):657-664

Shi XM, Zhang XW, Chen F (2002) Heterotrophic production of biomass and lutein by Chlorella protothecoides in heterotrophic fed-batch culture. Biotechnol Prog 18:723-727

Singh M, Reynolds DL, Das KC (2011) Microalgal system for treatment of effluent from poultry litter anaerobic digestion. Bioresour Technol 102:10841-10848

Sun N, Wang Y, Li YT, Huang JC, Chen F (2008) Sugar-based growth, astaxanthin accumulation and carotenogenic transcription of heterotrophic Chlorella zofingiensis (Chlorophyta). Process Biochem 43(11):1288-1292

Takagi M, Karseno, Yoshida T (2006) Effect of salt concentration on intracellular accumulation of lipids and triacylglyceride in marine microalgae Dunaliella cells. J Biosci Bioeng 101(3):223-226

Ummalyma SB, Sukumaran RK (2014) Cultivation of microalgae in dairy effluent of oil production and removal of organic pollution load. Bioresour Technol 165:295-301

Vazhappilly R, Chen F (1998) Eicosapentaenoic acid and docosahexaenoic acid production potential of microalgae and their heterotrophic growth. J Am Oil Chem Soc 75(3):393-397 
Vonshak A (1986) Laboratory techniques for the cultivation of microalgae. In: Richmond A (ed) Handbook of microalgal mass culture. CRC Press, Boca Raton, pp 117-145

Weissman JC, Tillett DM (1992) Design and operation of an outdoor microalgae test facility: Large-scale system results. In: Brown LM, Sprague S (eds) Aquatic species project report (FY 1989-90). National Renewable Energy Laboratory, Golden, NREL/TP-232-4174. pp 32-56
Wen ZY, Chen F (2003) Heterotrophic production of eicosapentaenoic acid by microalgae. Biotechnol Adv 21(4):273-294

Wiley PE, Brenneman KJ, Jacobson AE (2009) Improved algal harvesting using suspended air floatation. Water Environ Res 81(7):702-708

Witt V, Borchardt JA (1960) The removal of nitrogen and phosphorus from sewage effluents through the use of algal culture. J Biochem Microbiol Technol Eng 11(2):187-203 